\title{
Mossy cell hypertrophy and synaptic changes in the hilus following mild diffuse traumatic brain injury in pigs
}

Michael R. Grovola ${ }^{1,2}$, Nicholas Paleologos ${ }^{1,2}$, Kathryn L. Wofford ${ }^{1,2,3}$, James P. Harris ${ }^{1,2}$, Kevin D. Browne ${ }^{1,2}$, Victoria Johnson ${ }^{2}$, John E. Duda ${ }^{1,4,5}$, John A. Wolf ${ }^{1,2}$ and D. Kacy Cullen ${ }^{1,2,6^{*}}$

\begin{abstract}
Background: Each year in the USA, over 2.4 million people experience mild traumatic brain injury (TBI), which can induce long-term neurological deficits. The dentate gyrus of the hippocampus is notably susceptible to damage following TBI, as hilar mossy cell changes in particular may contribute to post-TBI dysfunction. Moreover, microglial activation after TBI may play a role in hippocampal circuit and/or synaptic remodeling; however, the potential effects of chronic microglial changes are currently unknown. The objective of the current study was to assess neuropathological and neuroinflammatory changes in subregions of the dentate gyrus at acute to chronic time points following mild TBI using an established model of closed-head rotational acceleration induced TBI in pigs.

Methods: This study utilized archival tissue of pigs which were subjected to sham conditions or rapid head rotation in the coronal plane to generate mild TBI. A quantitative assessment of neuropathological changes in the hippocampus was performed via immunohistochemical labeling of whole coronal tissue sections at 3 days postinjury (DPI), $7 \mathrm{DPI}, 30 \mathrm{DPI}$, and 1 year post-injury (YPI), with a focus on mossy cell atrophy and synaptic reorganization, in context with microglial alterations (e.g., density, proximity to mossy cells) in the dentate gyrus.

Results: There were no changes in mossy cell density between sham and injured animals, indicating no frank loss of mossy cells at the mild injury level evaluated. However, we found significant mossy cell hypertrophy at 7 DPI and $30 \mathrm{DPI}$ in anterior ( $>16 \%$ increase in mean cell area at each time; $p=<0.001$ each) and $30 \mathrm{DPI}$ in posterior (8.3\% increase; $p=<0.0001$ ) hippocampus. We also found dramatic increases in synapsin staining around mossy cells at $7 \mathrm{DPI}$ in both anterior (74.7\% increase in synapsin labeling; $p=<0.0001)$ and posterior ( $82.7 \%$ increase; $p=<$ 0.0001) hippocampus. Interestingly, these morphological and synaptic alterations correlated with a significant change in microglia in proximity to mossy cells at 7 DPI in anterior and at 30 DPI in the posterior hippocampus. For broader context, while we found that there were significant increases in microglia density in the granule cell layer at $30 \mathrm{DPI}$ (anterior and posterior) and 1 YPI (posterior only) and in the molecular layer at 1 YPI (anterior only), we found no significant changes in overall microglial density in the hilus at any of the time points evaluated postinjury.

(Continued on next page)
\end{abstract}

\footnotetext{
* Correspondence: dkacy@pennmedicine.upenn.edu

${ }^{1}$ Center for Neurotrauma, Neurodegeneration \& Restoration, Corporal

Michael J. Crescenz VA Medical Center, Philadelphia, PA, USA

${ }^{2}$ Center for Brain Injury \& Repair, Department of Neurosurgery, University of

Pennsylvania, 105E Hayden Hall/3320 Smith Walk, Philadelphia, PA 19104,

USA

Full list of author information is available at the end of the article
}

(c) The Author(s). 2020 Open Access This article is distributed under the terms of the Creative Commons Attribution 4.0 International License (http://creativecommons.org/licenses/by/4.0/), which permits unrestricted use, distribution, and

reproduction in any medium, provided you give appropriate credit to the original author(s) and the source, provide a link to the Creative Commons license, and indicate if changes were made. The Creative Commons Public Domain Dedication waiver (http://creativecommons.org/publicdomain/zero/1.0/) applies to the data made available in this article, unless otherwise stated. 
(Continued from previous page)

Conclusions: The alterations of mossy cell size and synaptic inputs paired with changes in microglia density around the cells demonstrate the susceptibility of hilar mossy cells after even mild TBI. This subtle hilar mossy cell pathology may play a role in aberrant hippocampal function post-TBl, although additional studies are needed to characterize potential physiological and cognitive alterations.

Keywords: Mild traumatic brain injury, Concussion, Microglia, Hippocampus, Mossy cell

\section{Background}

Every year, over 2.4 million people experience mild traumatic brain injury (TBI) [1]. Recent studies suggest that even mild TBI may be associated with long-term neurological deficits such as post-concussive syndrome and epilepsy $[2,3]$. One previous study using the current injury model has revealed synaptic dysfunction and regional hyperexcitability in the hippocampus, a structure essential for memory formation, after a single mild TBI [4]. Indeed, other studies have shown that mild TBI may induce neuropathological changes in the hippocampus, with the hilar region showing particular vulnerability to cell loss or aberrant axonal sprouting in preclinical models of TBI [5-8]. Mossy cells, the principal glutamatergic neuron of the hilus, are of particular interest due to their hallmark loss in temporal lobe epilepsy and potential role in post-TBI dysfunction $[5,9,10]$.

In addition, evidence suggests critical interplay between neuronal dysfunction, synaptic remodeling, and inflammatory processes. For example, recent studies on synaptic component changes and the development of neuronal hyperexcitability suggest that inflammation may be a contributing factor [11]. Genes associated with proinflammatory pathways are upregulated in patients with temporal lobe epilepsy and hippocampal sclerosis [12]. Additionally, human patients with temporal lobe epilepsy and hippocampal sclerosis, as well as rodents in experimental models of epilepsy, have displayed histopathological activation of macrophages, the primary peripheral innate immune cells that can access the brain following an insult, and microglia, the resident immune cells of the central nervous system [13]. In particular, rodent epilepsy studies have demonstrated that microglial processes are recruited by hyperactive neurons $[14,15]$. Importantly, synaptic inputs can be modified by microglia in both healthy and disease states: microglia have been shown to engulf and eliminate synapses during normal neuronal development [16-19], as well as during ongoing adult neurogenesis [20] and the progression of Alzheimer's disease [21]. While the precise role of microglia following TBI is still unclear, activated microglia have been shown in areas of neuronal damage in both human and animal models [22-25].

Overall, previous research has suggested that the hilus is vulnerable after TBI in other models, and that changes in hilar mossy cells may contribute to aberrant hippocampal function post-TBI. Therefore, using a rotationacceleration closed head injury model in pigs, the current study seeks to histologically examine synaptic changes and microglial activity around hilar mossy cells. We hypothesized that microglia will be more active in the hippocampal hilus and that there will be mossy cell loss following mild TBI.

\section{Methods}

All procedures were approved by the Institutional Animal Care and Use Committees at the University of Pennsylvania and the Michael J. Crescenz Veterans Affairs Medical Center and adhered to the guidelines set forth in the NIH Public Health Service Policy on Humane Care and Use of Laboratory Animals (2015).

Specimens used for the current study were from a tissue archive derived from castrated male pigs subjected to a single mild TBI. These 5-6-month-old, sexually mature (considered to be young adult), Yucatan miniature pigs at a mean weight of $34 \pm 4 \mathrm{~kg}(n=28$, mean \pm SEM $)$ were fasted for $16 \mathrm{~h}$ then anesthesia was induced with $20 \mathrm{mg} / \mathrm{kg}$ of ketamine and $0.5 \mathrm{mg} / \mathrm{kg}$ of midazolam. After induction, $0.1 \mathrm{mg} / \mathrm{kg}$ of glycopyrrolate was subcutaneously administered and $50 \mathrm{mg} / \mathrm{kg}$ of acetaminophen was administered per rectum. All animals were intubated with an endotracheal tube and anesthesia was maintained with $2 \%$ isoflurane per $2 \mathrm{l} \mathrm{O}_{2}$. Heart rate, respiratory rate, arterial oxygen saturation, and temperature were continuously monitored throughout the experiment. A forced-air temperature management system was used to maintain normothermia throughout the procedure.

In order to attain closed-head diffuse mild TBI in animals, we used a previously described model of head rotational-acceleration in pigs [26, 27]. Briefly, each animal's head was secured to a bite plate, which itself was attached to a pneumatic actuator and a custom assembly that converts linear motion into angular momentum. The pneumatic actuator rotated each animal's head in the coronal plane at a target angular velocity of 260 $\mathrm{rad} / \mathrm{s}$ (Fig. 1a). Any presence of apnea was recorded and animals were hemodynamically stabilized if necessary. Sham animals $(n=13)$ underwent identical protocols, including being secured to the bite plate; however, the 


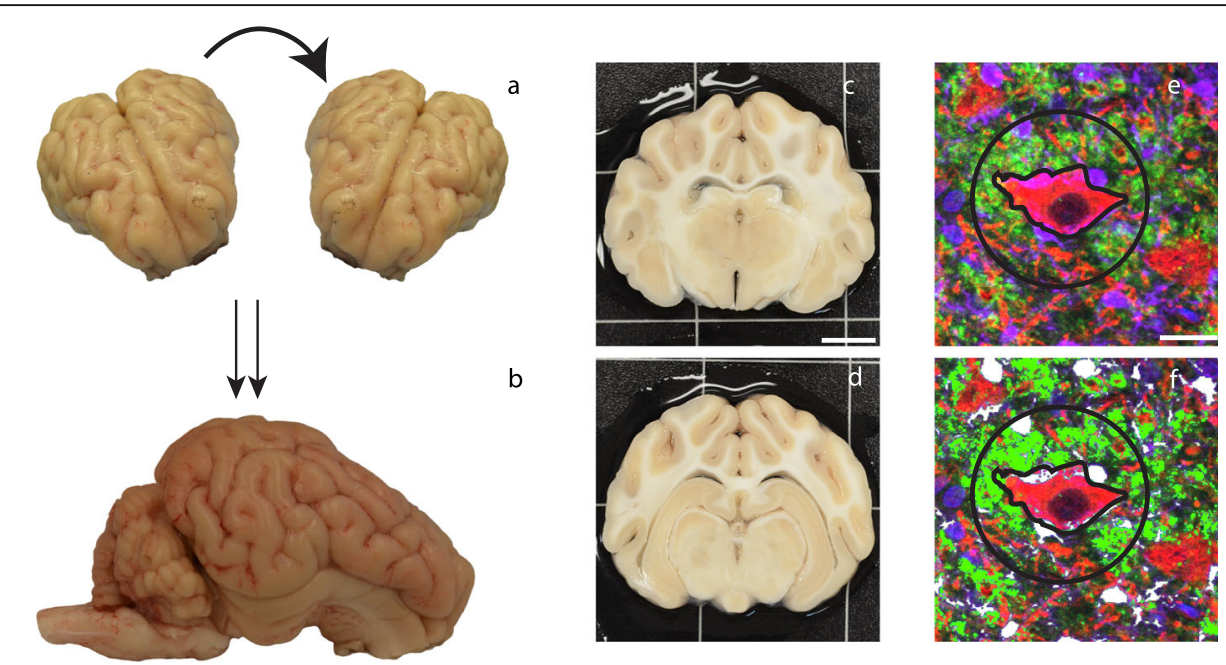

Fig. 1 Injury model and analysis methodology. a A rostral view of an extracted pig brain. The arrow demonstrates the coronal plane rotation. b A sagittal view of an extracted pig brain. The right arrow shows the location of the anterior hippocampal tissue $(\mathbf{c}$; $s c a l e ~ b a r=1 \mathrm{~cm})$, while the left arrow shows the location of the posterior hippocampal tissue (d). e All tissue was imaged on a confocal microscope for Hoechst (blue), synapsin (green), MAP2 (red), and Iba-1 (purple). After imaging, each mossy cell was outlined to obtain the area of each cell and a 30- $\mu$ m radius circle was created around the epicenter of each mossy cell (scale bar $=20 \mu \mathrm{m}$ ). $\mathbf{f}$ Highlights the extent of positive pixels detected by the Nikon Elements software, which were analyzed for the current study. Synapsin-positive pixels are shown in neon green and Iba-1-positive pixels are shown in white

pneumatic actuator was not initiated. All animals were transported back to their housing facility, monitored acutely for $3 \mathrm{~h}$, and given access to food and water. Afterwards, animals were monitored daily for 3 days by veterinary staff.

At 3 days post-injury (DPI) $(n=4), 7$ DPI $(n=5), 30$ DPI $(n=3)$, or 1 year post-injury (YPI) $(n=3)$, animals were induced and intubated as described above. Sham animals survived for 0 days $(n=1), 7$ days $(n=4), 14$ days $(n=2), 30$ days $(n=1)$, or 1 year $(n=5)$. While under anesthesia, animals were transcardially perfused with $0.9 \%$ heparinized saline followed by $10 \%$ neutral buffered formalin (NBF). Animals were then decapitated and tissue stored overnight in $10 \% \mathrm{NBF}$ at $4{ }^{\circ} \mathrm{C}$. The following day, the brain was extracted and post-fixed in $10 \% \mathrm{NBF}$ at $4{ }^{\circ} \mathrm{C}$ for 1 week. To block the tissue, an initial coronal slice was made immediately rostral to the optic chiasm. The brain was then blocked into 5-mm-thick coronal sections from that point by the same investigator. This allowed for consistent blocking and section coordinates across animals. All blocks of tissue were paraffin embedded and $8-\mu \mathrm{m}$-thick sections were obtained using a rotary microtome. Two sections from each specimen-one containing anterior aspects of hippocampal tissue (approximately $10 \mathrm{~mm}$ posterior to the optic chiasm) and one containing posterior aspects of hippocampal tissue (approximately $15 \mathrm{~mm}$ posterior to the optic chiasm) were used for the ensuing histological analysis. Though their functionality in the hippocampus cannot be distinguished at this time, the anterior and posterior aspects of hippocampal tissue have different gross anatomies and the forces induced by closed-head TBI may act differently on these regions. Anterior and posterior sections were used to provide more histological insight and be more representative of the hippocampus as a whole (Fig. 1c, d).

For fluorescence immunohistochemical labeling, slides were dewaxed in xylene, and rehydrated in ethanol and deionized water. Antigen retrieval was completed in Tris EDTA buffer $\mathrm{pH} 8.0$ using a microwave pressure cooker then blocked with normal horse serum. Slides were incubated overnight at $4{ }^{\circ} \mathrm{C}$ using anti-mouse synapsin I (Synaptic Systems, 106-001, 1:5000), anti-chicken Microtubule Associated Protein 2 (MAP2) (Abcam, ab5392, 1: 1000), and anti-rabbit Iba-1 (Wako, 019-19741, 1:1000) primary antibodies. The following day, sections were rinsed in PBS and incubated in donkey anti-mouse 488 (Invitrogen, A21202, 1:500), donkey anti-chicken 594 (Jackson Laboratories, 703-585-155, 1:500), and donkey anti-rabbit 647 (Invitrogen, A31573, 1:500) secondary antibodies for $60 \mathrm{~min}$. Sections were rinsed again, then incubated with Hoechst (Life Technologies, H3570, 1: 10000) to visualize DNA, and finally, coverslipped using Fluoromount-G (Southern Biotech, 0100-01). All sections were stained in the same histological sample run. All stained sections were imaged and analyzed at $\times 20$ optical zoom and $\times 1.5$ digital zoom using a Nikon A1R Confocal microscope. Z-plane acquisition was determined by detectable fluorescent labeling; the brightest synapsin fluorescent signal in the $z$-plane was the center 
point for $z$-stacked images. Each acquired $z$-stack was seven steps at $1.1 \mu \mathrm{m}$ spacing and was held consistent throughout all tissues. Each $z$-stack was then flattened to a 2D maximum projection. Representative images are shown in Fig. 3.

For 3,3'-diaminobenzidine (DAB) immunohistochemical labeling, we used a protocol outlined in Johnson et al. [28]. Briefly, slides were also dewaxed in xylene, rehydrated in ethanol, and deionized in water. Antigen retrieval was completed in Tris EDTA buffer $\mathrm{pH} 8.0$ using a microwave pressure cooker then blocked with normal horse serum. Slides were incubated overnight at $4{ }^{\circ} \mathrm{C}$ using an anti-rabbit Iba-1 (Wako, 019-19741, 1: 4000) primary antibody. The following day, slides were rinsed in PBS and incubated in a horse anti-mouse/ rabbit biotinylated IgG secondary antibody (VECTASTAIN Elite ABC Kit, Vector Labs, PK-6200). Sections were rinsed again, then incubated with an avidin/biotinylated enzyme complex (VECTASTAIN Elite ABC Kit), rinsed again, and incubated with the DAB enzyme substrate (Vector Labs, SK-4100) for $7 \mathrm{~min}$. Sections were counterstained with hematoxylin, dehydrated in ethanol, cleared in xylene, and finally coverslipped using cytoseal. All sections were stained in the same histological sample run. All sections were imaged and analyzed at $\times 20$ optical zoom using an Aperio CS2 digital slide scanner (Leica Biosystems Inc., Buffalo Grove, IL).

For quantitative analysis, the left hemisphere hippocampal hilus of each DAB-stained specimen was used. The left hemisphere was chosen as it has generally exhibited increased axonal pathology as this is the leading hemisphere in our head rotation injury model in the coronal plane [26, 29]. All slide identifications were blinded then subregions of the hippocampus were identified: hilus, granule cell layer (GCL), and molecular layer (ML). The examined molecular layer was defined as the area between the granule cell layer and the visible perforant path fibers. The granule cell layer included all visible granule cells. The examined hilus included all regions containing visible mossy cells immediately deep to the granule cell layer. We then counted all Iba-1positive cells in each region using the ImageJ software. Briefly, images were converted to grayscale and deconvoluted, and the "Analyze Particles" plug-in was used to count cells. Particles less than $20 \mu \mathrm{m}^{2}$ were excluded as these tended to be DAB-stained microglial processes in the field of view, detached from a microglial cell body. Blinded, semiquantitative, morphological assessment was also conducted on these Iba-1-positive cells in each hippocampal subregion. Microglia were considered active if they had shorter, thicker processes, while non-reactive microglia had longer, fine processes. Similar to Lafrenaye et al., the degree of microglial activation was assessed using a graded scale from 0 to $3(0=$ no microglial activation observed, $1=$ ramified microglia with shorter, thicker processes in less than $10 \%$ of the region, $2=$ activated microglia in $10-25 \%$ of the region, $3=$ activated microglia in $>25 \%$ of the region) [25].

For fluorescent specimen analysis, the left hemisphere hippocampal hilus of each specimen was again subject to quantitative analysis. All annotations and analyses were conducted blinded. Mossy cells were identified by their location in the subgranular zone of the hilus and distinguished by their larger size and larger synaptic clouds compared to interneurons. Scharfman and Myers have proposed a list of additional criteria to identify mossy cells, such as tracing mossy cell axon innervation to the inner molecular layer as well as a series of physiological characteristics; however, these criteria could not be assessed in the archival tissue used in the current study [30]. We identified mossy cells in time-matched sham $(n=72), 7$ DPI $(n=117)$, and 30 DPI $(n=89)$ anterior hippocampal tissue, as well as in time-matched sham $(n=346), 7$ DPI $(n=349)$, and 30 DPI $(n=304)$ posterior hippocampal tissue. Posterior hippocampal tissue has a larger area than anterior hippocampal tissue, so a greater number of mossy cells were anticipated in posterior hippocampus. All mossy cells in the section of the tissue were included in the analysis if they had a visible soma and nucleus. Using the Nikon Elements software, a region of interest was drawn around each mossy cell with a visible soma (Fig. 1e). This allowed us to obtain the area of each mossy cell. Additionally, a $30-\mu \mathrm{m}$ radius circle was drawn around the epicenter of each cell so that we could assess mossy cell synaptic clouds and microglia in close proximity to mossy cells. The use of a $30-\mu \mathrm{m}$ ROI was observationally determined from a pilot study, as this ROI seemed to include all synapsin clouds and microglia changes around mossy cells. While our previous study utilized a $60-\mu \mathrm{m}$ ROI, that study examined a different neuroanatomical area (cortex) and a different level of injury (moderate TBI), so microglial activity was anticipated to be different. The synapsin staining within the $30-\mu \mathrm{m}$ circle was thresholded and quantified for sum intensity using the Nikon Elements software, resulting in a single synapsin sum intensity value for each identified mossy cell. Iba-1-positive microglia were counted within the $30-\mu \mathrm{m}$ radius circle and included in the analysis if they also had visible Hoechst-positive nuclei (Fig. 1e,f).

Statistical analysis was performed using the GraphPad Prism statistical software (GraphPad Software Inc. La Jolla, CA). All immunohistochemical quantification was assessed via one-way analysis of variance (ANOVA) and Tukey's multiple comparisons test. One-way ANOVA results are reported as $F=$ (degrees of freedom numerator/degrees of freedom denominator) $F$ value, $p$ value). For the synapsin protein expression and mossy cell soma 
size analysis, the total number of cells within the defined hilar region was assessed. This approach allows for a within-subject analysis to assess the variance of soma size and synapsin expression within each individual specimen and also serves as a type of repeated measure. Nonparametric two-sample Kolmogorov-Smirnov (K-S) tests were used to compare the cumulative distribution of two datasets. Mean, standard error of the mean, and 95\% confidence intervals were reported. Additionally, Cohen's $d$ serves as a standardized metric of the magnitude of the reported effects. Differences were considered significant if $p<0.05$. As this was an archival study, power calculations were not used to determine the number of specimens for each experimental group; the current study used all available specimens exposed to a single mild TBI.

\section{Results}

Hilar mossy cell density did not change after mild TBI

We performed detailed quantitative cell-level studies in pig tissue sections at 7 DPI and 30 DPI versus sham to provide an in-depth analysis of microglial and synaptic changes around hilar mossy cells following mild TBI. Although other studies have found protein-specific markers for mossy cells in rodents and humans, there is no reported marker for mossy cells in pig tissue [31, 32]. Consequently, mossy cells were distinguished from hilar interneurons by their large size, somatic and dendritic morphology, and large synaptic clouds (Fig. 2).

Previous literature suggests that TBI may initiate mossy cell death; therefore, we sought to quantify potential mossy cell loss after mild TBI in our model. In anterior hippocampal hilus $(F=(2 / 9) 0.05112, p=$ $0.9504)$, mossy cell loss was not detected at 7 DPI $\left(\right.$ mean $=22.55$ cells $\left./ \mathrm{mm}^{2}, \quad \mathrm{SEM} \pm 3.048\right) \quad(p=0.9456$, $d=0.20$ ) or 30 DPI (mean $=22.03$ cells $/ \mathrm{mm}^{2}, \mathrm{SEM} \pm$ 1.153) $(p=0.9885, d=0.22) \quad$ compared with sham $\left(\right.$ mean $=21.48$ cells $\left./ \mathrm{mm}^{2}, \quad \mathrm{SEM} \pm 1.702\right)$. There was also no evidence of mossy cell loss between 7 DPI and 30 DPI $(p=0.9890, d=0.11)$ (Fig. 2o). Moreover, in the posterior hippocampal hilus, there was also no detectable mossy cell loss $(F=(2 / 9)$ 0.1524, $p=$ $0.8608)$. There was no significant difference in the number of mossy cells in sham (mean $=24.99$ cells $/$ $\left.\mathrm{mm}^{2}, \mathrm{SEM} \pm 3.879\right)$ compared to 7 DPI (mean $=22.90$ cells $\left./ \mathrm{mm}^{2}, \mathrm{SEM} \pm 3.399\right)(p=0.8911, d=0.27)$ or 30 DPI (mean $=22.45$ cells $\left./ \mathrm{mm}^{2}, \quad \mathrm{SEM} \pm 0.5451\right) \quad(p=$ $0.8774, d=0.46$ ). Additionally, there was no significant difference between 7 DPI and 30 DPI $(p=$ 0.9955, $d=0.08$ ) (Fig. 2p).

\section{Mossy cell hypertrophy at $\mathbf{7}$ and $\mathbf{3 0}$ days after mild TBI}

To examine potentially subtler mossy cell pathology, we determined the area of the mossy cell somata as a means to measure cell hypertrophy (Fig. 3). In anterior hippocampal hilus $(F=(2 / 275) 8.992, p=0.0002)$, mossy cell soma size increased at 7 DPI (mean $=584.3 \mu \mathrm{m}^{2}, \mathrm{SEM} \pm$ 14.89) $(p=0.0004, d=0.60)$ and 30 DPI $($ mean $=$ $\left.583.8 \mu \mathrm{m}^{2}, \mathrm{SEM} \pm 13.55\right)(p=0.0009, d=0.66)$ compared to sham (mean $\left.=502.2 \mu \mathrm{m}^{2}, \mathrm{SEM} \pm 14.07\right)$. There was no statistical difference in mossy cell size between 7 DPI and 30 DPI ( $p=0.997, d=0.003)$. Histograms of mossy soma size in anterior hilus further illustrate mossy cell hypertrophy after mild TBI as the data distribution shifts rightward, indicating an overall soma area increase at 7 DPI and 30 DPI compared to sham (Fig. 3j, l, and n). Two-sample K-S tests also support a change in the mossy cell area data distribution; there is a significant difference in data distribution between sham and 7 DPI $(p=0.0003)$, and sham and 30 DPI $(p=0.0001)$, but not 7 DPI and 30 DPI $(p=0.4549)$.

In posterior hippocampal hilus $(F=(2 / 996) 12.87, p<$ $0.0001)$, mossy cell soma size increased at 30 DPI $\left(\right.$ mean $\left.=649.5 \mu \mathrm{m}^{2}, \quad \mathrm{SEM} \pm 8.938\right)$ compared to sham $\left(\right.$ mean $\left.=599.5 \mu \mathrm{m}^{2}, \quad \mathrm{SEM} \pm 8.212\right) \quad(p=<0.0001, d=$ 0.32 ) and 7 DPI (mean $=594.0 \mu \mathrm{m}^{2}, \quad \mathrm{SEM} \pm 7.853$ ) $(p=<0.0001, d=0.37)$. There was no statistical difference in mossy cell size between sham and 7 DPI ( $p=$ $0.8816, d=0.04$ ). Histograms of the mossy soma size in posterior tissue show a rightward shift of the data distribution at 30 DPI compared to sham and 7 DPI, further demonstrating mossy cell hypertrophy after mild TBI (Fig. 3y, aa, and cc). Two-sample K-S tests also support a change in the mossy cell area data distribution; there is no significant difference in distribution between sham and 7 DPI $(p=0.2359)$, but there is a significant difference between 7 DPI and 30 DPI (0.0001), and sham and 30 DPI $(p=0.0006)$.

\section{Synapsin-positive staining increased at 7 days after mild TBI}

As there were significant changes in the mossy cell area, we postulated that local synaptic circuitry may have been remodeled after mild TBI [33]. Therefore, to histologically assess synaptic changes, we looked at the synaptic inputs to the mossy cells themselves. The sum intensity of synapsin, a presynaptic vesicle marker, was measured in a $30-\mu \mathrm{m}$ radius circle ROI around each mossy cell. This sum intensity is a metric for the total amount of secondary antibody fluorescent molecules bound to synapsin I proteins and therefore a measure of synapsin expression. As such, synapsin staining was used as a surrogate to assess the synaptic connections between the mossy cells and the granule cell layer.

This analysis revealed that, in anterior hippocampal hilus $(F=(2 / 217) 21.06, p<0.0001)$, synapsin labeling increased over 1.5 -fold at 7 DPI (mean $=3,886,994$ AU, $\mathrm{SEM} \pm 216,504)$ compared to sham (mean $=2,224,889$ 


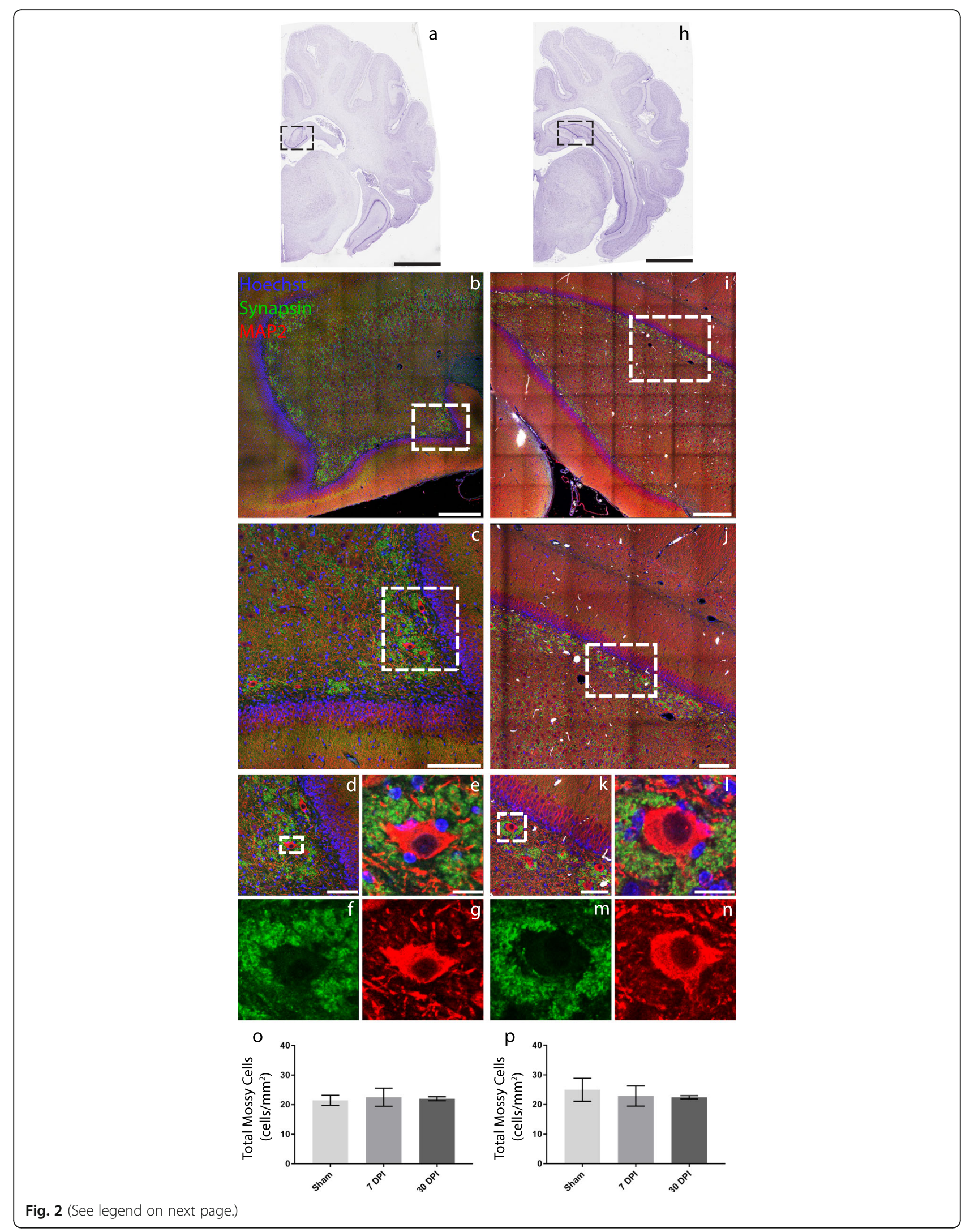


(See figure on previous page.)

Fig. 2 Immunohistochemical labeling reveals mossy cell morphology, but no cell loss following mild TBl. Coronal sections of pig brain containing the anterior (a) and posterior (h) levels of hippocampus used for the current analysis (scale $=1 \mathrm{~mm}$ ). $\mathbf{b}$ The call-out box in $\mathbf{a}$ is labeled for Hoechst—a fluorescent DNA marker, synapsin - a presynaptic vesicle marker, and MAP2 - a microtubule associated protein (scale $=500 \mu \mathrm{m})$. $\mathbf{c}$ A zoom-in of the call-out box in $\mathbf{b}($ scale $=200 \mu \mathrm{m})$. $\mathbf{d}$ A zoom-in of the call-out box in $\mathbf{c}($ scale $=100 \mu \mathrm{m})$. $\mathbf{e}-\mathbf{g}$ A single cell view of an anterior hilar mossy cell from the call-out box in $\mathbf{d}$. The overlay of all fluorescent labels is depicted (e), while the individual labels of synapsin (f) and MAP2 (g) are also shown $($ scale $=20 \mu \mathrm{m})$. $\mathbf{i}$ The call-out box in $\mathbf{h}$ is labeled for Hoechst, synapsin, and MAP2 $(s c a l e=500 \mu \mathrm{m})$. $\mathbf{j}$ A zoom-in of the call-out box in $\mathbf{i}($ scale $=250 \mu \mathrm{m})$. $\mathbf{k}$ A zoom-in of the call-out box in $\mathbf{j}($ scale $=100 \mu \mathrm{m})$. I-n A single cell view of a posterior hilar mossy cell from the callout box in $\mathbf{k}$. The overlay of all fluorescent labels is depicted (I), while the individual labels of synapsin (m) and MAP2 (n) are also shown (scale= $20 \mu \mathrm{m})$. Bar graphs of the total number of mossy cells in anterior $(\mathbf{o})$ and posterior $(\mathbf{p})$ sections show that there is no frank loss of mossy cells following mild TBI

$\mathrm{AU}, \mathrm{SEM} \pm 149,115)(p=<0.0001, d=0.92)$. Synapsin labeling then decreased at $30 \mathrm{DPI}$ (mean $=2,532,768 \mathrm{AU}$, $\mathrm{SEM} \pm 182,770)$ compared to 7 DPI $(p=<0.0001, d=$ 0.76 ), effectively returning to baseline (sham levels). There was no statistical difference in synapsin labeling between sham and 30 DPI specimens $(p=0.6367, d=$ $0.25)$. Histograms of synapsin sum intensity reveal the frequency of greater synapsin labeling at 7 DPI compared to 30 DPI and sham. Specifically, we can see the synapsin sum intensity for sham specimens peaked around $2 \times 10^{6} \mathrm{AU}$ and began to steadily drop off to a maximum of $5 \times 10^{6} \mathrm{AU}$. Thirty DPI specimens also reached a maximum for sum intensity at $5 \times 10^{6} \mathrm{AU}$ but seem to have a bimodal distribution of data with peaks at $2 \times 10^{6} \mathrm{AU}$ and $4 \times 10^{6} \mathrm{AU}$. Notably, 7 DPI specimens had a less obvious data peak but had $33 \%$ of ROI synapsin sum intensities between $5 \times 10^{6} \mathrm{AU}$ and $8 \times 10^{6} \mathrm{AU}$, while sham and 30 DPI had only $1 \%$ of their total data points in this higher range (Fig. $3 \mathrm{k}, \mathrm{m}$, and o). Twosample K-S tests also supported this synapsin labeling change at 7DPI: sham and 7 DPI $(p=0.0001)$, as well as 7 DPI and 30 DPI $(p=0.0018)$, had significantly different data distributions, while sham and 30 DPI $(p=0.1556)$ did not.

In the posterior hippocampal hilus $(F=(2 / 970) 55.23$, $p<0.0001)$, synapsin labeling increased over 1.5 -fold at 7 DPI (mean $=3,828,213 \mathrm{AU}, \mathrm{SEM} \pm 225,361$ ) compared to sham $($ mean $=2,095,759$ AU, SEM $\pm 70,190)(p=<0.0001$, $d=0.53$ ) yet decreased at $30 \mathrm{DPI}($ mean $=1,389,796 \mathrm{AU}$, SEM $\pm 117,217)$ compared to both 7 DPI $(p=<0.0001$, $d=0.74)$ and sham $(p=0.0158, d=0.46)$. Histograms of synapsin sum intensity again reveal the frequency of greater synapsin labeling at $7 \mathrm{DPI}$ compared to $30 \mathrm{DPI}$ and sham. Specifically, sham synapsin sum intensity reached a maximum at $6 \times 10^{6} \mathrm{AU}$ and $30 \mathrm{DPI}$ sum intensity reached a maximum at $1 \times 10^{7} \mathrm{AU}$, whereas $7 \mathrm{DPI}$ had $17 \%$ of ROI synapsin sum intensities greater than $1 \times$ $10^{7} \mathrm{AU}$ and reached a maximum at $1.5 \times 10^{7} \mathrm{AU}$ (Fig. 3z, $\mathrm{bb}, \mathrm{dd})$. Two-sample K-S tests also supported this synapsin labeling change between experimental groups: sham and 7 DPI $(p=0.0001)$, sham and 30 DPI $(p=0.0001)$, and 7 DPI and 30 DPI $(p=0.0001)$ all have significantly different data distributions.

\section{Microglia density around mossy cells change following mild TBI}

To examine the potential migration of microglia in the hilus after injury, we counted Iba-1-positive cells with visible Hoechst-positive nuclei within a $30-\mu \mathrm{m}$ radius circle ROI around each mossy cell (Fig. 4). In anterior hippocampal hilus $(F=(2 / 9) 2.648, p=0.1247)$, there were no significant differences in ROI microglia density at 7 DPI (mean $=441.9$ cells $\left./ \mathrm{mm}^{2}, \mathrm{SEM} \pm 45.45\right) \quad(p=$ $0.1377, d=1.74$ ) and 30 DPI (mean $=449.3$ cells $/ \mathrm{mm}^{2}$, $\mathrm{SEM} \pm 103) \quad(p=0.2258, d=1.16)$ compared to sham $\left(\right.$ mean $=617.1$ cells $\left./ \mathrm{mm}^{2}, \quad \mathrm{SEM} \pm 49.94\right)$. Furthermore, there was no significant change between 7 DPI and 30 DPI ( $p=0.9962, d=0.05)$ (Fig. $4 \mathrm{j})$. Using a histogram to provide further detail of ROI microglia density, we plotted the number of microglia around each mossy cell. We observed a leftward shift in the data distribution at 7 DPI and 30 DPI compared to sham suggesting that most mossy cells from 7 DPI or 30 DPI specimens had zero or one microglia within the ROI, while most mossy cells from sham specimens had two or more microglia within the ROI (Fig. 4l). Two-sample K-S tests reveal that the sample distribution of the number of ROI microglia was significantly different between sham and 7 DPI $(p=$ $0.0095)$ but not between 7 DPI and 30 DPI $(p=0.9997)$ or sham and 30 DPI $(p=0.1693)$, which suggests that 7 DPI specimens have less microglia within the ROI more frequently compared to sham.

We then assessed the direct interaction of Hoechstpositive microglia with mossy cells $(F=(2 / 9) 4.064, p=$ 0.0553). There were no significant differences in the number of microglia contacting mossy cells per square millimeter at 7 DPI (mean $=233.3$ cells $/ \mathrm{mm}^{2}, \mathrm{SEM} \pm$ 21.81) $(p=0.0889, d=1.36)$ and 30 DPI (mean $=212.8$ cells $\left./ \mathrm{mm}^{2}, \mathrm{SEM} \pm 5.897\right)(p=0.0794, d=1.73)$ compared to sham $\left(\right.$ mean $=352.3$ cells $\left./ \mathrm{mm}^{2}, \mathrm{SEM} \pm 56.66\right)$. There was no significant difference between 7 DPI and 30 DPI $(p=0.9223, d=0.58)$ (Fig. $4 \mathrm{k})$. We also plotted a histogram of the number of microglia directly contacting each mossy cell (Fig. 4m). Sham specimens had a normal distribution of data; approximately $40 \%$ of sham mossy cells have one contacting microglia while approximately $25 \%$ had zero and another $25 \%$ had two contacting 


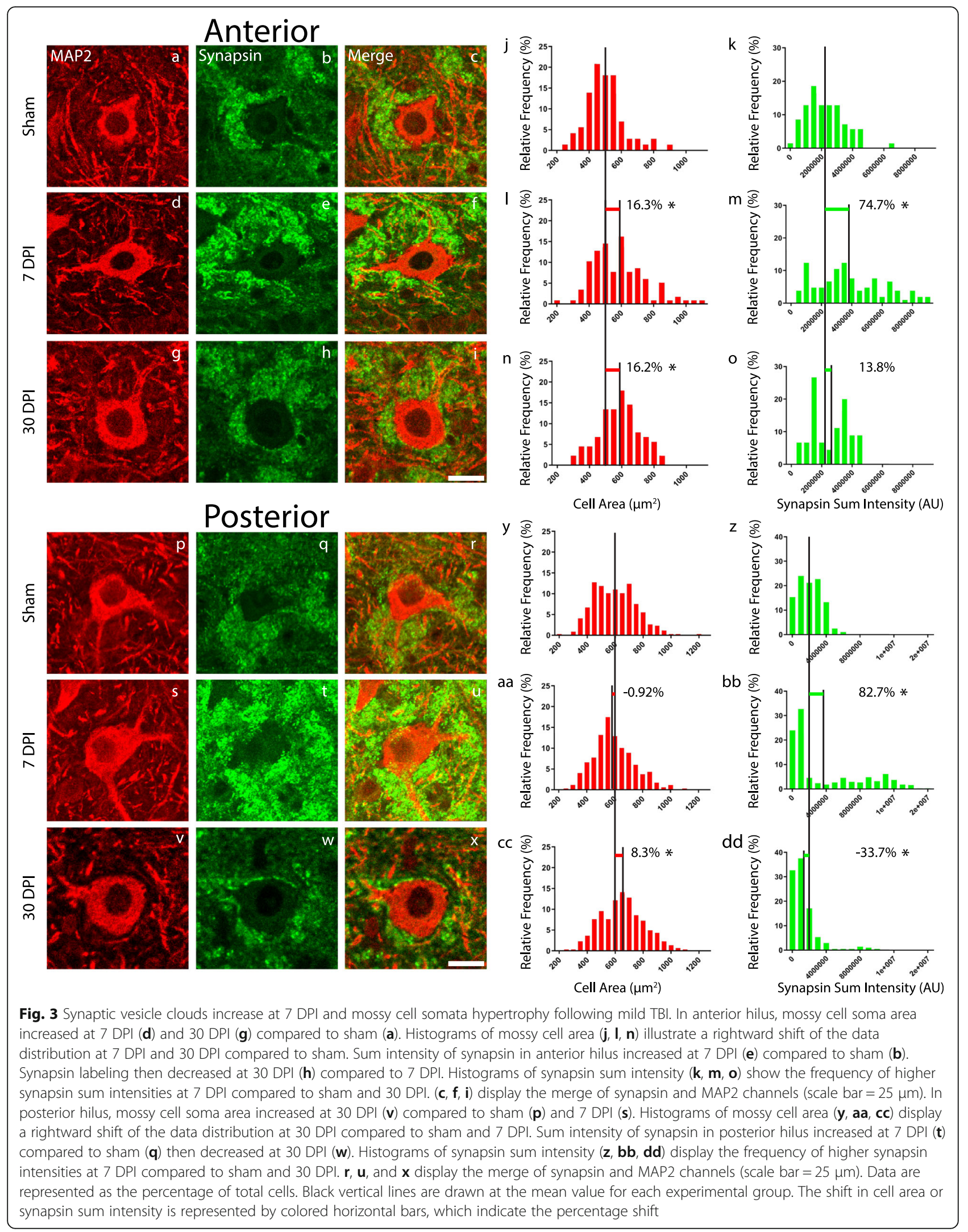




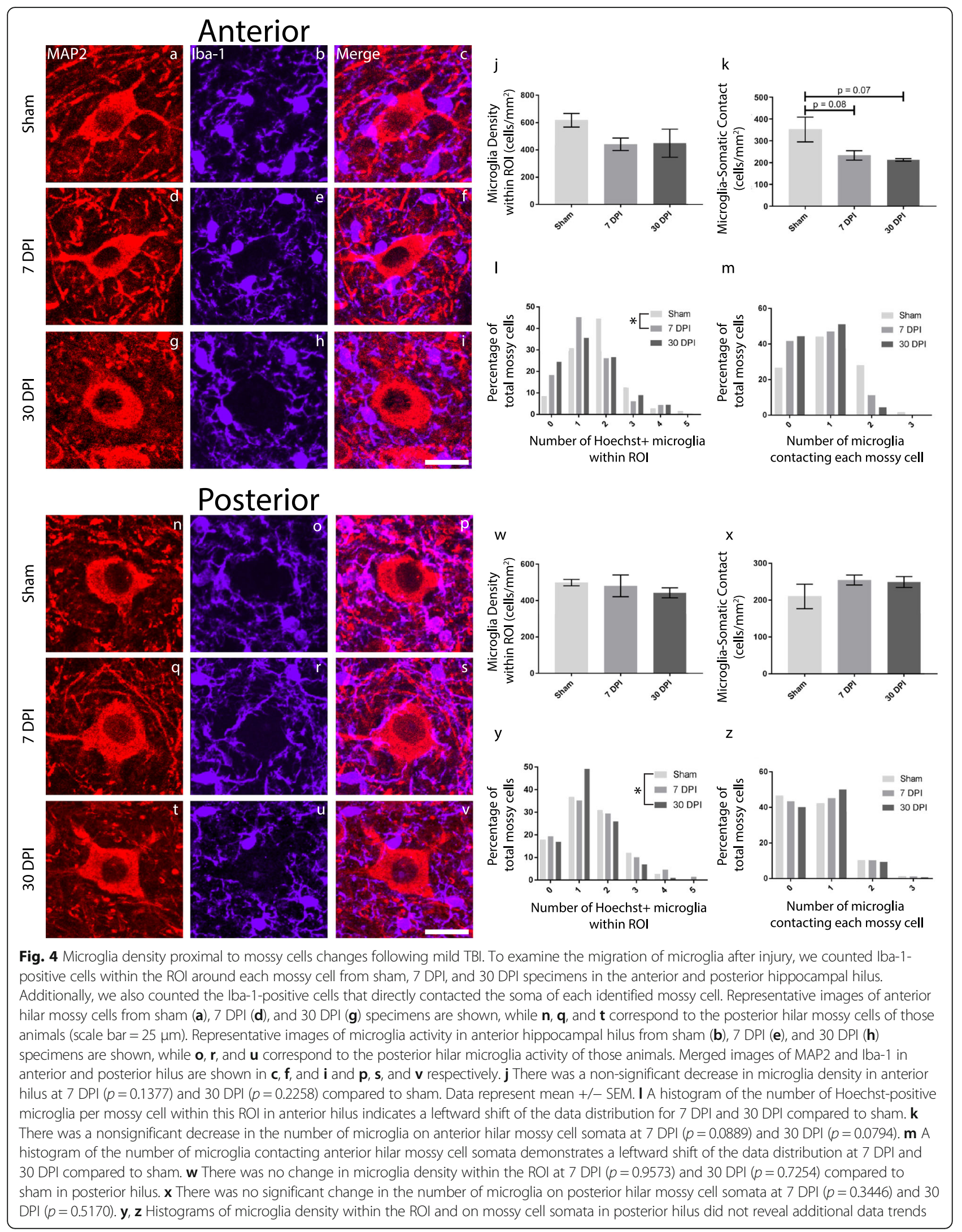


microglia. In comparison, 7 DPI and 30 DPI specimens had a leftward shift of the data distribution; over $85 \%$ of 7 DPI or 30 DPI mossy cells have zero or one microglia contacting the soma. However, two-sample K-S tests revealed that the sample distribution of the number of microglia contacting each mossy cell was not significantly different between sham and 7 DPI $(p=0.1213), 7$ DPI and 30 DPI $(p=0.9981)$, or sham and 30 DPI $(p=$ 0.0684)

In the posterior hippocampal hilus $(F=(2 / 9)$ $0.3085, \quad p=0.7420)$, there were no significant changes in ROI microglia density at 7 DPI $($ mean $=$ 481 cells $\left./ \mathrm{mm}^{2}, \quad \mathrm{SEM} \pm 59.72\right) \quad(p=0.9573, \quad d=0.18)$ and 30 DPI $\left(\right.$ mean $=442.9$ cells $\left./ \mathrm{mm}^{2}, \mathrm{SEM} \pm 27.5\right)$ $(p=0.7254, d=1.33)$ compared to sham (mean $=$ 498.8 cells $\left./ \mathrm{mm}^{2}, \quad \mathrm{SEM} \pm 17.67\right)$, nor was there a significant difference between 7 DPI and 30 DPI $(p=0.8471, d=0.38) \quad$ (Fig. $4 \mathrm{w})$. A histogram of this data revealed that 30 DPI specimens tended to have one microglia within the ROI more frequently than 7 DPI and sham (Fig. 4y). Two sample K-S tests support this observation as there was a significant difference in the data distribution of microglia density between 7 DPI and 30 DPI $(p=0.0252)$, as well as sham and 30 DPI $(p=0.0237)$, but not between sham and 7 DPI $(p=0.9956)$.

In addition, there were no significant differences in microglia contacting mossy cells per square millimeter in the posterior hippocampal hilus $(F=(2 / 9) 1.208, p=$ $0.3431)$ at 7 DPI (mean $=255.0$ cells $\left./ \mathrm{mm}^{2}, \mathrm{SEM} \pm 13.54\right)$ $(p=0.3446, d=0.87)$ and 30 DPI $\left(\right.$ mean $=249.4$ cells $/ \mathrm{mm}^{2}$, $\mathrm{SEM} \pm 14.69)(p=0.5170, d=0.78) \quad$ compared to sham $\left(\right.$ mean $=210.3$ cells $\left./ \mathrm{mm}^{2}, \mathrm{SEM} \pm 33.19\right)$, nor was there a significant difference between 7 DPI and 30 DPI $(p=$ $0.9842, d=0.20$ ) (Fig. 4x). A histogram of this data did not reveal additional trends (Fig. 4z). Finally, two-sample K-S tests suggest that the sample distribution is not different between sham and 7 DPI $(p=0.9960)$, or 7 DPI and 30 DPI $(p=0.9940)$, and sham and 30 DPI $(p=0.5162)$.

\section{Microglia density changes in additional hippocampal subfields over time post-injury}

In order to put the changes related to hilar moss cells, synapses, and microglia in a broader context, we measured microglial morphological and density changes across various hippocampal subfields related to the dentate gyrus. To provide a wider temporal context, these analyses were performed in tissue sections from pig subjects at 3 DPI, 7 DPI, 30 DPI, and 1 YPI following mild TBI (compared to age-matched sham animals). First, semiquantitative assessment of microglial morphology using a graded scale in the ML, GCL, and hilus of the hippocampus (at both anterior and posterior levels) revealed an absence of overtly activated microglia. Indeed, blinded assessment did not detect any changes in microglia morphology across groups or over time.

Therefore, we next measured microglia density in the ML, GCL, and hilus (at both anterior and posterior levels) at 3 DPI, 7 DPI, 30 DPI, and 1 YPI. Microglial density was also measured in age-matched sham animals; however, there were no differences in any of the sham groups out to 1 YPI, so these animals were combined into a single sham group for statistical analysis. Across the ML, GCL, and hilus, the same general trends were observed: a modest, but not significant, increase in microglial density at $3 \mathrm{DPI}$; a return to baseline by 7 DPI; and a second, non-significant increase again at 30 DPI which, in most cases, was sustained (or re-elevated) out to 1 YPI. However, microglia density changes were only statistically significant in the GCL $(F=(4 / 23) 2.880$, $p=0.0454)$ and $\mathrm{ML}(F=(4 / 23) 3.402, p=0.0252)$, but not the hilus $(F=(4 / 23) 1.567, p=0.2167)$ in anterior sections of hippocampus. Specifically, in anterior sections of hippocampal tissue, microglia density increased over 2.5-fold in both the GCL at 30 DPI (mean $=287.8$ cells $/ \mathrm{mm}^{2}, \mathrm{SEM} \pm 46.85$ ) compared to 7 DPI (mean $=$ $\left.109.5 \mathrm{cells} / \mathrm{mm}^{2}, \mathrm{SEM} \pm 16.76\right)(p=0.0312)$, as well as in the ML at 1 YPI (mean $=762.8$ cells $\left./ \mathrm{mm}^{2}, \mathrm{SEM} \pm 144.6\right)$ compared to 7 DPI (mean $=304.5$ cells $/ \mathrm{mm}^{2}, \mathrm{SEM} \pm$ 42.16) ( $p=0.0348)$ (Fig. 5). All descriptive statistics and multiple comparison significance values between anterior hippocampus experimental groups are summarized in Tables 1 and 2, respectively.

In posterior sections of hippocampal tissue, microglia density changes were only statistically significant in the GCL $(F=(4 / 22) 4.485, p=0.0084)$, but not the ML $(F=(4 / 23) 2.253, p=0.0946)$ or the hilus $(F=(4 / 22)$ 2.303, $p=0.0907)$. Microglia density increased over twofold in both the GCL at 30 DPI (mean $=384.6$ cells $/$ $\left.\mathrm{mm}^{2}, \mathrm{SEM} \pm 39.04\right)(p=0.0365)$ and 1 YPI (mean $=384.7$ cells $\left./ \mathrm{mm}^{2}, \mathrm{SEM} \pm 142.2\right)(p=0.0364)$ compared to sham $\left(\right.$ mean $=168.5$ cells $/ \mathrm{mm}^{2}, \mathrm{SEM} \pm 24.37$ ) (Fig. 6). All descriptive statistics and multiple comparison significance values between posterior hippocampus experimental groups are summarized in Tables 3 and 4, respectively. Of note, the density of "microglia" was determined based on the expression of Iba- $1^{+}$cells; however, we cannot rule out that the increase is Iba-1-positive cells found at certain time points post-injury also includes a component of infiltrating peripheral macrophages, which could also be Iba-1 positive.

Additionally, all observed microglia density changes were homogenous within each defined hippocampal subregion; no distinct microglia clustering was observed.

\section{Discussion}

A history of TBI is associated with cognitive impairment, such as short-term memory deficits and disrupted 


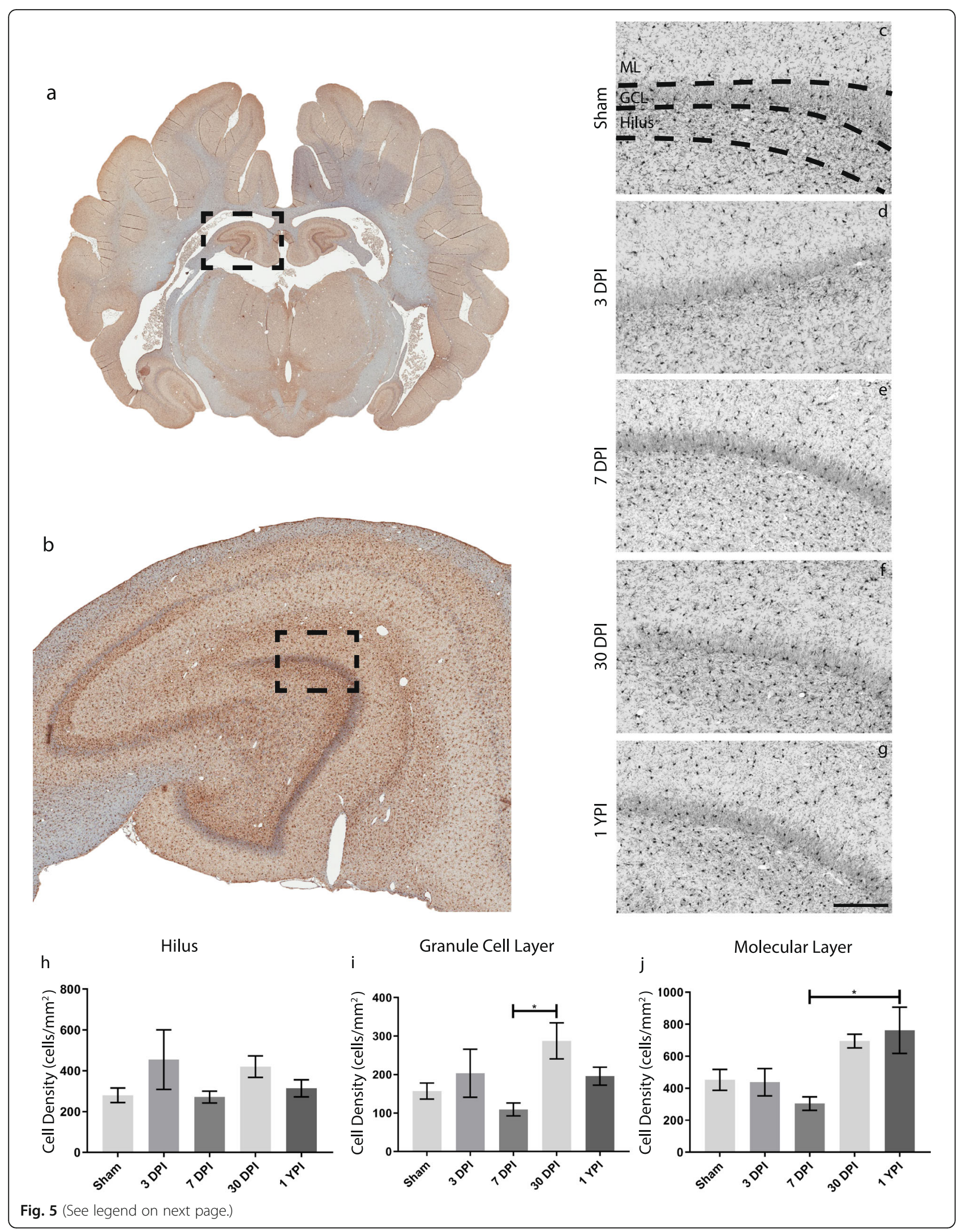


(See figure on previous page.)

Fig. 5 Microglia density increases in the anterior hippocampus over time following mild TBI. Microglia, stained with Iba-1, in pig coronal sections containing anterior hippocampus (a) with an enlarged call out box (b). The molecular layer (ML), granule cell layer (GCL), and Hilar region of the hippocampus were identified for each specimen and a representative image of Iba-1 staining for each experimental group is displayed (c- $\mathbf{g}$ ) $($ scale $=200 \mu \mathrm{m})$. Microglia cell counts are quantified and graphed $(\mathbf{h}-\mathbf{j})$. Overall, biphasic trends can be observed as microglia tended to increase at 3 days post-injury (DPI), then decrease at $7 \mathrm{DPI}$, and finally increase again at chronic timepoints. $\mathbf{i}$ There is a significant increase in microglia from $7 \mathrm{DPI}$ to $30 \mathrm{DPI}$ in the $\mathrm{GCL}(p=0.0312)$ and $\mathbf{j}$ a significant increase in microglia from $7 \mathrm{DPI}$ to 1 year post-injury (YPI) in the ML $(p=0.0348)$

cognitive processing, with even a single so-called mild TBI potentially leading to long-term changes in memory performance and hippocampal structure [34]. After a single mild TBI using our pig model of closed-head rotational-acceleration, while there was no evidence of mossy cell loss, we found significant mossy cell hypertrophy at 7 DPI and 30 DPI in anterior $(>16 \%$ increase in mean cell area at each time; $p=<0.001$ each) and 30 DPI in posterior $(8.3 \%$ increase; $p=<0.0001)$ hippocampus. We also found dramatic increases in synapsin staining around mossy cells at 7 DPI in both anterior $(74.7 \%$ increase in synapsin labeling; $p=<0.0001$ ) and posterior $(82.7 \%$ increase; $p=<0.0001)$ hippocampus. Interestingly, these alterations correlated with a significant change in microglia in proximity to mossy cells at $7 \mathrm{DPI}$ in anterior and at 30 DPI in the posterior hippocampus via K-S tests. For broader context, while we found that there were significant increases in microglia density in the granule cell layer at 30 DPI (anterior and posterior) and 1 YPI (posterior only) and in the molecular layer at 1 YPI (anterior only), we found no significant changes in overall microglial density in the hilus at any of the time points evaluated post-injury. No overt changes in microglial morphology indicative of activation (i.e., shorter, thickened processes) were observed in any of the hippocampal subfields at any of the time points evaluated. Our hypothesis was that microglia would be more active in the hippocampal hilus and that there will be mossy cell loss following mild TBI. Based on our findings, we are compelled to reject this hypothesis.

In the current study, we initially examined the state of the mossy cells themselves. As noted, we hypothesized that mossy cells would be lost after mild TBI. Yet, unlike previous rodent studies, we did not observe any mossy cell loss in our mild TBI model-at the mild injury level that we applied [5-8]. Specifically, the number of mossy cells per unit area did not change between sham, 7 DPI, or 30 DPI. Nevertheless, subtler mossy cell changes were observed. Mossy cells hypertrophied at 7 DPI and 30 DPI in anterior tissue and at 30 DPI in posterior tissue. It is also unclear why the anterior and posterior mossy cell data are disparate. Mossy cell axonal projections are variable depending on their location within the hippocampus according to rodent literature, yet we are unsure if this translates to pig hippocampal architecture [30, 35]. It is possible that, similar to rodents, pig hilar mossy cell connections may be affected differently following mild TBI depending on their location within the hippocampus. Yet, some of the detected changes may be due to the differences in our injury models; the closed-head rotation acceleration injury model produces a diffuse brain injury while the rodent FPI model requires removal of part of the skull and generally results in tissue disruption [36]. Mossy cell loss may be seen in different injury models or at higher injury levels, but a single mild TBI in our pig model appears to induce a subtler mossy cell pathology. Future studies should extend these results across escalating injury levels to ascertain threshold loading parameters for mossy cell loss following closed-head rotational acceleration induced TBI.

We next examined the potential for synaptic changes to the mossy cells. In anterior and posterior tissue, we found an increase in synapsin I, a marker of pre-synaptic vesicles, staining at 7 DPI compared to both sham and 30 DPI. This increased synapsin is inconsistent with other hippocampal TBI literature. In a rodent controlled cortical impact model, synapsin I expression decreased in the ipsilateral hippocampus at 7 and 21 DPI [37, 38]. Synapsin I loss has been documented even at $24 \mathrm{~h}$ after TBI, with researchers suggesting that synapsin I loss is a

Table 1 Microglia density in anterior hippocampal tissue. All values are reported as mean \pm standard error mean, 95\% confidence interval [lower 95\% Cl, upper 95\% Cl]

\begin{tabular}{|c|c|c|c|}
\hline & Hilus & Granule cell layer & Molecular layer \\
\hline Sham & 280.2 cells $/ \mathrm{mm}^{2} \pm 35.53,95 \% \mathrm{Cl}[202.7,357.6]$ & 157.2 cells $/ \mathrm{mm}^{2} \pm 20.80,95 \% \mathrm{Cl}[111.9,202.5]$ & 452.6 cells $/ \mathrm{mm}^{2} \pm 65.50,95 \% \mathrm{Cl}[309.8,595.3]$ \\
\hline 3 DPI & 455.1 cells $/ \mathrm{mm}^{2} \pm 146.1,95 \% \mathrm{Cl}[-9.7,920.0]$ & 203.4 cells $/ \mathrm{mm}^{2} \pm 62.30,95 \% \mathrm{Cl}[5.155,401.7]$ & $/ \mathrm{mm}^{2} \pm 85.33,95 \% \mathrm{Cl}[166.1,709.2]$ \\
\hline 7 DPI & 271.6 cells $/ \mathrm{mm}^{2} \pm 28.94,95 \%$ Cl $[191.2,351.9]$ & 109.5 cells $/ \mathrm{mm}^{2} \pm 16.76,95 \% \mathrm{Cl}[62.94,156.0]$ & 304.5 cells $/ \mathrm{mm}^{2} \pm 42.16,95 \% \mathrm{Cl}[187.4,421.5]$ \\
\hline 30 DPI & 420.2 cells $/ \mathrm{mm}^{2} \pm 52.69,95 \%$ Cl $[193.5,646.8]$ & 287.8 cells $/ \mathrm{mm}^{2} \pm 46.85,95 \% \mathrm{Cl}[86.18,489.4]$ & 695.1 cells $/ \mathrm{mm}^{2} \pm 42.96,95 \% \mathrm{Cl}[510.2,879.9]$ \\
\hline 1 YPI & 314.4 cells $/ \mathrm{mm}^{2} \pm 42.06,95 \% \mathrm{Cl}[133.4,495.4]$ & 195.8 cells $/ \mathrm{mm}^{2} \pm 23.38,95 \%$ Cl $[95.23,296.5]$ & 762.8 cells $/ \mathrm{mm}^{2} \pm 144.6,95 \% \mathrm{Cl}[140.8,1385]$ \\
\hline
\end{tabular}


Table 2 Microglia density $p$ values in the anterior hippocampus. All values displayed are the adjusted $p$ values following a Tukey's multiple comparisons test and Cohen's $d$ effect size

\begin{tabular}{llll}
\hline & Hilus & Granule cell layer & Molecular layer \\
\hline Sham vs. 3 DPI & $p=0.2616, d=0.77$ & $p=0.8291, d=0.45$ & $p>0.9999, d=0.07$ \\
Sham vs. 7 DPI & $p>0.9999, d=0.08$ & $p=0.7631, d=0.80$ & $p=0.6336, d=0.82$ \\
Sham vs. 30 DPI & $p=0.5807, d=1.25$ & $p=0.0939, d=1.67$ & $p=0.3532, d=1.38$ \\
Sham vs. 1 YPI & $p=0.996, d=0.32$ & $p=0.9327, d=0.64$ & $p=0.1481, d=1.27$ \\
3 DPI vs. 7 DPI & $p=0.3651, d=0.87$ & $p=0.3866, d=1.02$ & $p=0.8579, d=0.97$ \\
3 DPI vs. 30 DPI & $p=0.9978, d=0.16$ & $p=0.6123, d=0.80$ & $p=0.4665, d=1.95$ \\
3 DPI vs. 1 YPI & $p=0.7211, d=0.66$ & $p>0.9999, d=0.08$ & $p=0.2462, d=1.52$ \\
7 DPI vs. 30 DPI & $p=0.6435, d=1.88$ & $p=0.0312, d=2.82$ & $p=0.0916, d=4.60$ \\
7 DPI vs. 1 YPI & $p=0.9943, d=0.62$ & $p=0.5503, d=2.21$ & $p=0.0348, d=2.42$ \\
30 DPI vs. 1 YPI & $p=0.9009, d=1.28$ & $p=0.5951, d=1.43$ & $p=0.9935, d=0.37$ \\
\hline
\end{tabular}

result of increased oxidative stress [39]. However, research on the mossy cells themselves has found enhanced action potential discharges in response to perforant path stimulation after rodent FPI, as researchers have hypothesized that mossy cells may be vulnerable to injury as a result of presynaptic mechanisms [5, 40]. In a mouse model of temporal lobe epilepsy, Zhang et al. observed a reduction of input resistance to mossy cells, as well as a frequency increase of miniature postsynaptic currents in epileptic mice, indicating an overall increase in excitatory synaptic input to mossy cells [33]. Interestingly, Jinde et al. used a transgenic mouse line to ablate mossy cells, which resulted in granule cell excitability but no detection of epileptiform activity [41]. In contrast, Bui et al. optogenetically inhibited mossy cells in a mouse model of temporal lobe epilepsy and observed that spontaneous electrographic seizures progressed into convulsive seizures [42]. Yet, this does not fully explain our detected decrease in synapsin at 30 DPI compared to 7 DPI. Future experiments with our current model should conduct whole-cell electrophysiology recordings to characterize potential functional changes to mossy cells in conjunction with the observed histological increase in presynaptic inputs. Nonetheless, our findings show that elements of circuit remodeling occur absent mossy cell loss following a single mild TBI. This circuit level disruption is supported by previous research from our group. In ex vivo hippocampal slices, dentate gyrus and CA1 recordings displayed reduced axonal function, regional hyperexcitability, and elevated excitatory post-synaptic potential at 7 DPI versus sham animals. These physiological changes occurred absent neuronal or axonal degeneration [4].

We also sought to examine microglia density proximal to hilar mossy cells, which are thought to be prone to damage and potential phagocytosis following TBI [5-8]. In addition, microglia may prune mossy cell synapses and therefore play a role in the decrease in presynaptic input at $30 \mathrm{DPI}$ versus the stark increase in presynaptic input at 7 DPI. For instance, Eyo et al. noted that glutamate induced microglia to extend their processes towards hippocampal neurons and that knocking out the P2Y12 receptor in microglia worsened seizure behavior in a rodent model of epilepsy [14]. As such, we counted microglia density within a $30-\mu$ m radius circle around each mossy cell. While we did observe a trend of lower microglia densities at 7 DPI and 30 DPI compared to sham in anterior tissue, it was not statistically significant. We then assessed the direct interaction of microglia with mossy cells and found no significant differences in the number of microglia contacting mossy cells at $7 \mathrm{DPI}$ $(p=0.0889)$ and 30 DPI $(p=0.0794)$ compared to sham. There was no noticeable trend for microglia activity changes in posterior tissue. However, K-S tests detected a significant change in the sample distribution of microglia within the ROI at certain time points. Therefore, future studies should closely monitor the activity of microglia, potentially by quantifying the alteration of synaptic components between 7 DPI and 30 DPI. Previous research using this pig model of injury noted an increase in microglia activity proximal to acutely injure neurons exhibiting plasma membrane damage [22]. However, the dye injection used to track membrane permeability is a terminal procedure, and thus, incompatible with a chronic study. Moreover, this previous work did not select specific anatomically defined cells or regions as was done in the current study, but rather used a sensitive marker of subtle neuronal injury to direct examinations of microglial morphology and density. Therefore, investigations focusing on regions showing marked pathology may be necessary to see large effect sizes in closed-head diffuse TBI that lacks any macroscale injury epicenter.

To explore a potential role of microglial activation in mossy cell hypertrophy and synaptic remodeling, we 


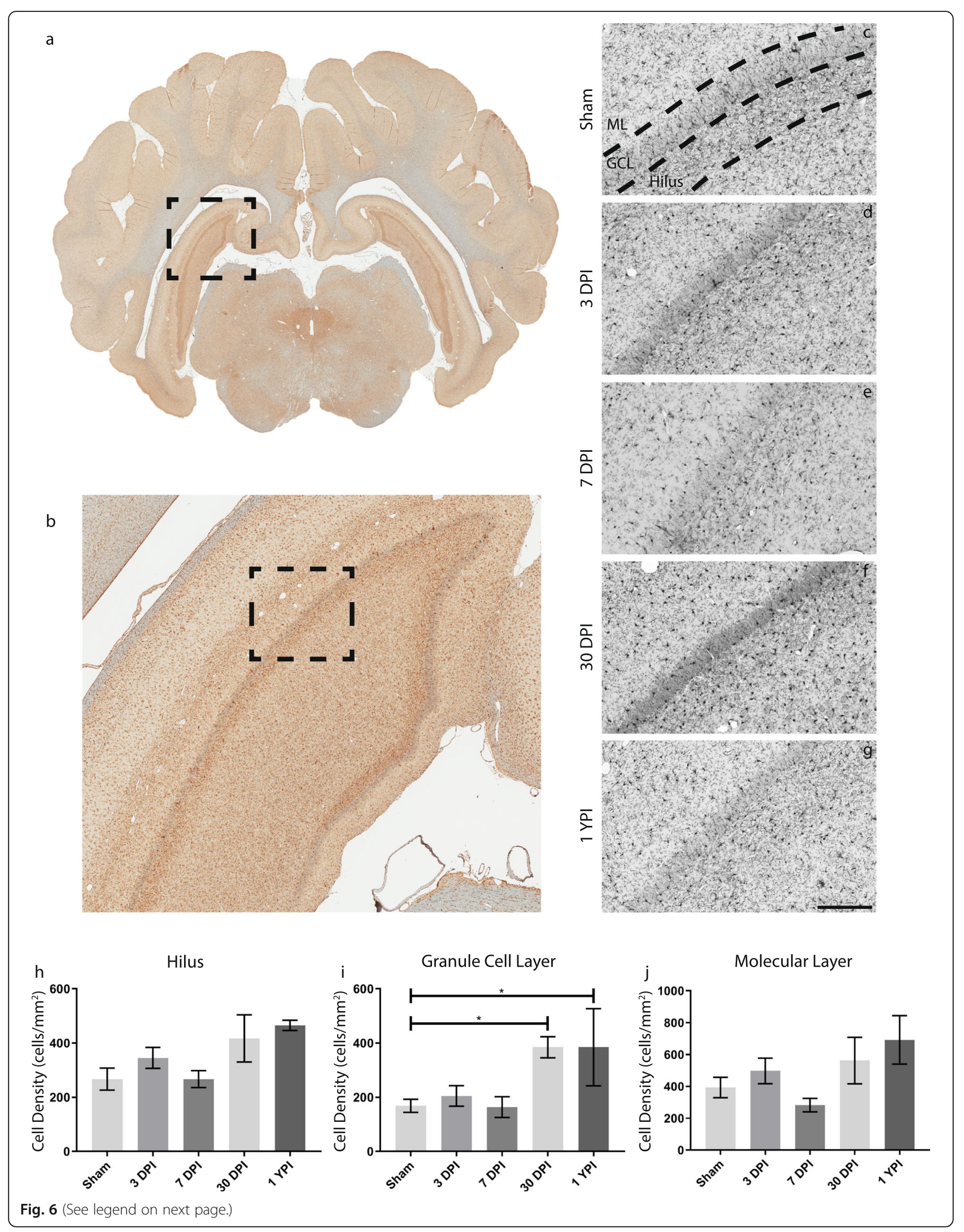


(See figure on previous page.)

Fig. 6 Microglia density increases in the posterior hippocampus over time following mild TBI. Microglia in pig coronal sections containing posterior hippocampus (a) with an enlarged call out box (b). The ML, GCL, and Hilar region of the hippocampus were identified for each specimen and a representative image of Iba-1 staining for each experimental group is displayed $(\mathbf{c}-\mathbf{g})(\mathrm{scale}=200 \mu \mathrm{m})$. Microglia cell counts are quantified and graphed $(\mathbf{h}-\mathbf{j})$. Like the anterior hippocampus, biphasic trends can be observed as microglia tended to increase at 3 DPI, then decrease at $7 \mathrm{DPl}$, and finally increase again at chronic timepoints. $\mathbf{i}$ There is a significant increase in microglia in the GCL at $30 \mathrm{DPI}(p=0.0365)$ and 1 YPI $(p=0.0364)$ compared to sham

next expanded our examination of microglial responsiveness to larger areas in and around the hilar region of the hippocampus. We initially hypothesized that microglia activity would increase in the hilus following mild TBI. However, our cell density counts indicate a more complex microglial response throughout the dentate gyrus. In anterior sections, there was a significant increase in cell density at 30 DPI compared to 7 DPI in the granule cell layer and a significant increase at 1 YPI compared to 7 DPI in the molecular layer. In posterior sections, there was an increase at 30 DPI and 1 YPI compared to sham in the granule cell layer. These examples of continuing microglia density changes may correspond to chronic phases of inflammation post-injury that previous literature has suggested; however, as noted, there were not morphological changes in microglia which runs contrary to conventionally accepted definitions of "neuroinflammation" that generally features an increased incidence of reactive, ameboid microglia. Our observed changes in microglia density without changes in microglia morphology are dissimilar to the noted neuroinflammatory response in rodents subjected to fluid percussion injury and other models of pig TBI. Of note, Gorse and Lafrenaye examined rat and pig thalamus following central fluid percussion injury. At 1 DPI, rats displayed a decrease in microglial process interactions around amyloid precursor protein stained, injured axons while pigs displayed an increase in microglial interactions with injured axons compared to sham [43]. Components of neuroinflammatory response include but are not limited to driving neuronal cell death, synaptic pruning, release of growth signals, and sequestering pathological debris [18, 44-47]. More investigation is needed to determine what phenotype and behavior microglia are prioritizing in this model of mild TBI. A review on neuroinflammation after
TBI by Simon et al. summarizes that pathological proliferation of microglia is generally observed at $72 \mathrm{~h}$ after injury and peaks at 3 months, which is not inconsistent with our findings [48]. Additionally, chronically activated microglia were observed from 2 weeks to many years after TBI in human post mortem tissue, though this microglial response may also be influenced by several factors including age, sex, mechanism and degree of injury, and secondary insults [48]. Furthermore, rodent studies have noted an increase in activated microglia density at subacute and chronic time points starting at 1 week and up to 52 weeks after injury [23], which is also consistent with our findings although the method of inducing injury, the severity of the injury, and the experimental species are different than the current study. Future studies could investigate if these cells are pathological or detrimental to neuronal health or if these cells are playing a role in environmental support and synaptic remodeling/health.

Altered structure and function of mossy cells postinjury is relevant to one hypothesis suggesting that surviving mossy cells contribute to hyperexcitability and potential memory deficits following TBI [5]. This socalled irritable mossy cell hypothesis proposes that surviving mossy cells can grow aberrant axonal processes after TBI that projects into the granule cell layer creating excessive synaptic connections, as well as a positive excitable feedback loop to the hilus, which may contribute to the development of post-traumatic epilepsy [5, 9]. Moreover, mossy cell hypertrophy has been recorded in rodent models of epilepsy with some researchers theorizing that injured mossy cells may develop more cell machinery, and thus a larger cell body, to support axon sprouting $[33,49]$. However, more research is needed to determine if these rodent model results translate to our

Table 3 Microglia density in the posterior hippocampal tissue. All values are reported as mean \pm standard error mean, 95\% confidence interval [lower 95\% Cl, upper 95\% Cl]

\begin{tabular}{llll}
\hline & Hilus & Granule cell layer & Molecular layer \\
\hline Sham & 267.1 cells $/ \mathrm{mm}^{2} \pm 40.93,95 \% \mathrm{Cl}[177.9,356.2]$ & $168.5 \mathrm{cells} / \mathrm{mm}^{2} \pm 24.37,95 \% \mathrm{Cl}[115.4,221.6]$ & $393.6 \mathrm{cells} / \mathrm{mm}^{2} \pm 64.13,95 \% \mathrm{Cl}[253.9,533.3]$ \\
$3 \mathrm{DPI}$ & $345.1 \mathrm{cells} / \mathrm{mm}^{2} \pm 38.46,95 \% \mathrm{Cl}[222.7,467.5]$ & $205.1 \mathrm{cells} / \mathrm{mm}^{2} \pm 37.88,95 \% \mathrm{Cl}[84.57,325.6]$ & $497.6 \mathrm{cells} / \mathrm{mm}^{2} \pm 80.47,95 \% \mathrm{Cl}[241.5,753.7]$ \\
$7 \mathrm{DPI}$ & $267 \mathrm{cells} / \mathrm{mm}^{2} \pm 31.04,95 \% \mathrm{Cl}[168.2,365.8]$ & $164.0 \mathrm{cells} / \mathrm{mm}^{2} \pm 38.35,95 \% \mathrm{Cl}[41.95,286.0]$ & $282.9 \mathrm{cells} / \mathrm{mm}^{2} \pm 42.38,95 \% \mathrm{Cl}[165.3,400.6]$ \\
$30 \mathrm{DPI}$ & $417.2 \mathrm{cells} / \mathrm{mm}^{2} \pm 86.95,95 \% \mathrm{Cl}[43.07,791.3]$ & $384.6 \mathrm{cells} / \mathrm{mm}^{2} \pm 39.04,95 \% \mathrm{Cl}[216.6,552.6]$ & $562.8 \mathrm{cells} / \mathrm{mm}^{2} \pm 146.3,95 \% \mathrm{Cl}[-66.69,1192]$ \\
$1 \mathrm{YPI}$ & $465.2 \mathrm{cells} / \mathrm{mm}^{2} \pm 19.15,95 \% \mathrm{Cl}[382.8,547.6]$ & $384.7 \mathrm{cells} / \mathrm{mm}^{2} \pm 142.2,95 \% \mathrm{Cl}$ & $692.3 \mathrm{cells} / \mathrm{mm}^{2} \pm 152.3,95 \% \mathrm{Cl}[37.16,1347]$ \\
& & {$[-227.3,996.7]$} & \\
\hline
\end{tabular}


Table 4 Microglia density $p$ values in the posterior hippocampus. All values displayed are the adjusted $p$ values following a Tukey's multiple comparisons test and Cohen's $d$ effect size

\begin{tabular}{llll}
\hline & Hilus & Granule cell layer & Molecular layer \\
\hline Sham vs. 3 DPI & $p=0.8046, d=0.66$ & $p=0.9751, d=0.45$ & $p=0.9076, d=0.52$ \\
Sham vs. 7 DPI & $p>0.9999, d=0.0008$ & $p>0.9999, d=0.05$ & $p=0.8538, d=0.63$ \\
Sham vs. 30 DPI & $p=0.3514, d=1.00$ & $p=0.0365, d=2.76$ & $p=0.7215, d=0.70$ \\
Sham vs. 1 YPI & $p=0.1281, d=1.85$ & $p=0.0364, d=1.17$ & $p=0.2109, d=1.20$ \\
3 DPI vs. 7 DPI & $p=0.8973, d=1.12$ & $p=0.9824, d=0.54$ & $p=0.562, d=1.63$ \\
3 DPI vs. $30 \mathrm{DPI}$ & $p=0.9389, d=0.60$ & $p=0.2278, d=2.50$ & $p=0.994, d=0.31$ \\
3 DPI vs. 1 YPI & $p=0.7122, d=2.02$ & $p=0.2275, d=0.99$ & $p=0.7463, d=0.89$ \\
7 DPI vs. $30 \mathrm{DPI}$ & $p=0.5211, d=1.30$ & $p=0.0921, d=3.05$ & $p=0.3882, d=1.46$ \\
7 DPI vs. 1 YPI & $p=0.258, d=3.98$ & $p=0.0919, d=1.21$ & $p=0.0922, d=2.07$ \\
30 DPI vs. 1 YPI & $p=0.9889, d=0.44$ & $p>0.9999, d=0.001$ & $p=0.9415, d=0.50$ \\
\hline
\end{tabular}

pig model of mild TBI or human TBI. Future pig TBI studies should characterize this potential aberrant sprouting through immunohistochemistry or through viral axon tracers following injury.

Moreover, exploring the mechanisms that prime microglia responses, such as complement system activation and cytokine production, may be a crucial step in identifying therapeutic targets. Future measurements of changes in gene expression, which may quantify a wide array of inflammatory and synaptic RNA markers, followed by in situ hybridization, may provide an appropriate spatial resolution within whole sections of hippocampal tissue. These experiments would help confirm the potential inflammatory and synaptic alterations observed in the current study. Additional studies should also explore the significant increase in microglial density in the GCL at chronic time points. The increase in GCL microglia may be a response to the 7 DPI mossy cell synapsin levels. Microglia may be regulating GCL neurons themselves as granule cells provide much of the presynaptic inputs to the mossy cells. In particular, we can count the number of granule cell neurons, survey for ectopic neurons, and histologically assess perforant path inputs to the GCL and aberrant sprouting from the GCL after mild TBI. Moreover, while our current study only utilized postmortem structural markers, selective positron emission tomography (PET)- or magnetic resonance imaging (MRI)-based imaging methods would allow us to track putative neuroinflammation in a single subject over time, providing additional insight on the activity of microglia between our terminal time points. Finally, future studies should examine the effects of repetitive injuries on hippocampal alterations as microglia become more reactive and ameboid after repetitive injuries relative to single injuries [22]. Exposure to repetitive injuries may increase a patient's risk for hippocampal dysfunction.

\section{Conclusions}

Our pig model of closed-head rotational accelerationinduced diffuse TBI replicates key features of clinical TBI, including the biomechanical loading parameters underlying the pathogenesis of mild TBI and subsequent neuropathology in humans. Unlike rodents, pigs have a large brain mass, gyrencephalic brain architecture, and a gray to white matter ratio similar to humans [50-52]. This is particularly important because diffuse axonal injury in white matter is believed to be the principal pathology of closed-head diffuse TBI [53, 54]. The injury levels employed in this study were designed to biomechanically mimic levels associated with concussion in humans, and it is interesting that we did not observe mossy cell loss as shown in rodent preclinical models, but rather we found hilar mossy cell hypertrophy at 7 DPI and 30 DPI and an increase in synapsin staining at 7 DPI. This may be indicative of subtle mossy cell damage in concussion, aberrant sprouting between the mossy cells and granule cells, and potential hippocampal network hyperexcitability. However, the decrease in synapsin staining at 30 DPI may also indicate compensatory pruning, which would facilitate the removal of excess synaptic connections after TBI-induced damage. We also observed microglia density changes in the granule cell layer and molecular layer, but not the hilus, at certain time points following mild TBI in a clinically translatable model. Future studies should examine microglial modification of synaptic components and electrophysiological input and output changes related to mossy cells to confirm physiological circuitry changes. These studies would provide insight into the nexus of hippocampal circuit remodeling and neuroinflammatory processes, and thus may lend insight into hippocampal-related functional deficits following mild TBI. 


\section{Abbreviations}

DAB: 3,3'-Diaminobenzidine; DPI: Days post-injury; GCL: Granule cell layer; Iba-1: Ionized calcium-binding adapter molecule; ML: Molecular layer; MRI: Magnetic resonance imaging; NBF: Neutral buffered formalin; PET: Positron emission tomography; TBI: Traumatic brain injury; YPI: Year post-injury

\section{Acknowledgements}

The authors thank Dr. John O'Donnell, Dr. Patricia Shewokis, and Carolyn Keating for their guidance.

\section{Authors' contributions}

$M R G$, JED, JAW, and DKC designed the experiments. MRG, KLW, JPH, and KDB performed research. MRG and NP analyzed data. MRG and DKC wrote the paper. All authors read and approved the final manuscript.

\section{Funding}

This work was made possible through financial support provided by the Department of Veterans Affairs [RR\&D Merit Review 101-RX001097 (Duda), BLR\&D Merit Review 101- BX003748 (Cullen), and RR\&D Career Development Award IK2-RX001479 (Wolf)], the National Institutes of Health (NINDS R01-NS101108 (Wolf), NINDS T32-NS043126 (Harris)], the CURE Foundation [Taking Flight Award (Wolf)], the US Department of Defense [ERP CDMRP \#W81XWH16-1-0675 (Wolf)], and the National Science Foundation [STEMGK-12 program \#DGE-0947936 (Wofford)]. None of the funding sources aided in the collection, analysis, and interpretation of data, in the writing of the report, or in the decision to submit the paper for publication.

\section{Availability of data and materials}

The datasets used during the current study are available from the corresponding author on reasonable request.

\section{Ethics approval and consent to participate}

All procedures were approved by the Institutional Animal Care and Use Committees at the University of Pennsylvania and the Michael J. Crescenz Veterans Affairs Medical Center and adhered to the guidelines set forth in the NIH Public Health Service Policy on Humane Care and Use of Laboratory Animals (2015).

\section{Consent for publication}

Not applicable

\section{Competing interests}

The authors declare that they have no competing interests.

\section{Author details}

${ }^{1}$ Center for Neurotrauma, Neurodegeneration \& Restoration, Corporal Michael J. Crescenz VA Medical Center, Philadelphia, PA, USA. ${ }^{2}$ Center for Brain Injury \& Repair, Department of Neurosurgery, University of Pennsylvania, 105E Hayden Hall/3320 Smith Walk, Philadelphia, PA 19104, USA. ${ }^{3}$ School of Biomedical Engineering, Science and Health Systems, Drexel University, Philadelphia, PA, USA. ${ }^{4}$ Parkinson's Disease Research, Education and Clinical Center, Corporal Michael J. Crescenz VA Medical Center, Philadelphia, PA, USA. ${ }^{5}$ Department of Neurology, Perelman School of Medicine, University of Pennsylvania, Philadelphia, PA, USA. ${ }^{6}$ Department of Bioengineering, School of Engineering and Applied Science, University of Pennsylvania, 105E Hayden Hall/3320 Smith Walk, Philadelphia, PA 19104, USA.

Received: 1 May 2019 Accepted: 19 January 2020

Published online: 31 January 2020

\section{References}

1. Coronado VG, Mcguire LC, Sarmiento K, Bell J, Lionbarger MR, Jones CD, et al. Trends in traumatic brain injury in the US and the public health response: 1995-2009. J Safety Res. 2012;43(4):299-307. https://doi.org/10. 1016/j.jsr.2012.08.011.

2. Webb TS, Whitehead CR, Wells TS, Gore RK, Otte CN. Neurologically-related sequelae associated with mild traumatic brain injury. Brain Inj. 2015;29(4): 430-7 Available from: http://informahealthcare.com/doi/abs/10.3109/026 99052.2014.989904.
3. Hoge CW, McGurk D, Thomas JL, Cox AL, Engel CC, Castro CA. Mild traumatic brain injury in US soldiers returning from Iraq. N Engl J Med. 2008; 358(5):453-63 Available from: http://www.nejm.org/doi/abs/10.1056/ NEJMoa072972.

4. Wolf JA, Johnson BN, Johnson VE, Putt ME, Browne KD, Mietus CJ, et al. Concussion induces hippocampal circuitry disruption in swine. J Neurotrauma. 2017;34(14):2303-14 Available from: http://online.liebertpub. com/doi/10.1089/neu.2016.4848.

5. Santhakumar V, Bender R, Frotscher M, Ross ST, Hollrigel GS, Toth Z, et al. Granule cell hyperexcitability in the early post-traumatic rat dentate gyrus: the "irritable mossy cell" hypothesis. J Physiol. 2000;524 Pt 1:117-34 Available from: http://www.ncbi.nlm.nih.gov/pubmed/10747187.

6. Kharatishvili I, Nissinen JP, Mclntosh TK, Pitkänen A. A model of posttraumatic epilepsy induced by lateral fluid-percussion brain injury in rats. Neuroscience. 2006;140(2):685-97.

7. Smith DH, Lowenstein DH, Gennarelli TA, McIntosh TK. Persistent memory dysfunction is associated with bilateral hippocampal damage following experimental brain injury. Neurosci Lett. 1994;168(1-2):151-4 Available from: http://linkinghub.elsevier.com/retrieve/pii/0304394094904383.

8. Lowenstein DH, Thomas MJ, Smith DH, Mclntosh TK. Selective vulnerability of dentate hilar neurons following traumatic brain injury: a potential mechanistic link between head trauma and disorders of the hippocampus. J Neurosci. 1992;12(12):4846-53 Available from: http://www.ncbi.nlm.nih.gov/ pubmed/1464770

9. Ratzliff A d H, Santhakumar V, Howard A, Soltesz I. Mossy cells in epilepsy: rigor mortis or vigor mortis? Trends Neurosci. 2002;25(3):140-4 Available from: http://www.ncbi.nlm.nih.gov/pubmed/11852145.

10. Blumcke I, Suter B, Behle K, Schramm J, Elger CE, Wiestler D. Loss of hilar mossy cells in Ammon's horn sclerosis. Epilepsia. 2000;41(4):S174-80.

11. Vezzani A, Aronica E, Mazarati A, Pittman QJ. Epilepsy and brain inflammation. Exp Neurol. 2013;244:11-21.

12. Aronica E, Gorter JA. Gene expression profile in temporal lobe epilepsy. Neuroscientist. 2007;13(2):100-8 Available from: http://www.ncbi.nlm.nih. gov/pubmed/17404370

13. Ravizza T, Gagliardi B, Noé F, Boer K, Aronica E, Vezzani A. Innate and adaptive immunity during epileptogenesis and spontaneous seizures: evidence from experimental models and human temporal lobe epilepsy. Neurobiol Dis. 2008;29(1):142-60

14. Eyo UB, Peng J, Swiatkowski P, Mukherjee A, Bispo A, Wu L-J. Neuronal hyperactivity recruits microglial processes via neuronal NMDA receptors and microglial P2Y12 receptors after status epilepticus. J Neurosci. 2014;34(32): 10528-40 Available from: http://www.jneurosci.org/cgi/doi/10.1523/ JNEUROSCI.0416-14.2014.

15. Eyo UB, Murugan M, Wu L-J. Microglia-neuron communication in epilepsy. Glia. 2017;65(1):5-18 Available from: http://doi.wiley.com/10.1002/glia.23006. [cited 2019 Jul 5].

16. Stevens B, Allen NJ, Vazquez LE, Howell GR, Christopherson KS, Nouri N, et al. The classical complement cascade mediates CNS synapse elimination. Cell. 2007;131(6):1164-78.

17. Tremblay MĔ, Lowery RL, Majewska AK. Microglial interactions with synapses are modulated by visual experience. PLoS Biol. 2010;8(11).

18. Paolicelli RC, Bolasco G, Pagani F, Maggi L, Scianni M, Panzanelli P, et al. Synaptic pruning by microglia is necessary for normal brain development. Science. 2011;333(6048):1456-8 Available from: http://www.sciencemag.org/ cgi/doi/10.1126/science.1202529.

19. Schafer DP, Lehrman EK, Kautzman AG, Koyama R, Mardinly AR, Yamasaki R, et al. Microglia sculpt postnatal neural circuits in an activity and complement-dependent manner. Neuron. 2012;74(4):691-705. https://doi, org/10.1016/j.neuron.2012.03.026.

20. Sierra A, Encinas JM, Deudero JJP, Chancey JH, Enikolopov G, OverstreetWadiche LS, et al. Microglia shape adult hippocampal neurogenesis through apoptosis-coupled phagocytosis. Cell Stem Cell. 2010;7(4):483-95. https:// doi.org/10.1016/j.stem.2010.08.014.

21. Hong S, Beja-Glasser VF, Nfonoyim BM, Frouin A, Li S, Ramakrishnan S, et al. Complement and microglia mediate early synapse loss in Alzheimer mouse models. Science. 2016;352(6286):712-6 Available from: http://www. sciencemag.org/cgi/doi/10.1126/science.aad8373.

22. Wofford KL, Harris JP, Browne KD, Brown DP, Grovola MR, Mietus CJ, et al. Rapid neuroinflammatory response localized to injured neurons after diffuse traumatic brain injury in swine. Exp Neurol. 2017;290:85-94. https://doi.org/ 10.1016/j.expneurol.2017.01.004. 
23. Loane DJ, Kumar A, Stoica BA, Cabatbat R, Faden Al. Progressive neurodegeneration after experimental brain trauma. J Neuropathol Exp Neurol. 2014;73(1):14-29 Available from: https://academic.oup.com/jnen/ article-lookup/doi/10.1097/NEN.0000000000000021.

24. Johnson VE, Stewart JE, Begbie FD, Trojanowski JQ, Smith DH, Stewart W. Inflammation and white matter degeneration persist for years after a single traumatic brain injury. Brain. 2013;136(1):28-42.

25. Lafrenaye AD, Todani M, Walker SA, Povlishock JT. Microglia processes associate with diffusely injured axons following mild traumatic brain injury in the micro pig. J Neuroinflammation. 2015;12(1):186 Available from: http:// www.jneuroinflammation.com/content/12/1/186.

26. Smith DH, Chen XH, Xu BN, Mcintosh TK, Gennarelli TA, Meaney DF. Characterization of diffuse axonal pathology and selective hippocampal damage following inertial brain trauma in the pig. J Neuropathol Exp Neurol. 1997:56:822-34.

27. Cullen DK, Harris JP, Browne KD, Wolf JA, Duda JE, Meaney DF, et al. A porcine model of traumatic brain injury via head rotational acceleration. Methods Mol Biol. 2016;1462:289-324.

28. Johnson VE, Stewart W, Weber MT, Cullen DK, Siman R, Smith DH. SNTF immunostaining reveals previously undetected axonal pathology in traumatic brain injury. Acta Neuropathol. 2016;131(1):115-35 Available from: http://www.ncbi.nlm.nih.gov/pubmed/26589592.

29. Smith DH, Meaney DF. Axonal damage in traumatic brain injury. Porg Clin Neurosci. 2000;6(6):483-92.

30. Scharfman HE, Myers CE. Hilar mossy cells of the dentate gyrus: a historica perspective. Front Neural Circuits. 2013;6:1-17 Available from: http://journal. frontiersin.org/article/10.3389/fncir.2012.00106/abstract.

31. Duffy AM, Schaner MJ, Chin J, Scharfman HE, Al DET. Expression of c-fos in hilar mossy cells of the dentate gyrus in vivo. Hippocampus. 2013;23(8):64955 Available from: http://doi.wiley.com/10.1002/hipo.22138.

32. Abraham H, Czeh B, Fuchs E, Seress L, Ábrahám H, Czéh B, et al. Mossy cells and different subpopulations of pyramidal neurons are immunoreactive for cocaine- and amphetamine-regulated transcript peptide in the hippocampal formation of non-human primates and tree shrew (Tupaia belangeri). Neuroscience. 2005;136(1):231-40.

33. Zhang $W$, Thamattoor AK, Leroy C, Buckmaster PS. Surviving mossy cells enlarge and receive more excitatory synaptic input in a mouse model of temporal lobe epilepsy. Hippocampus. 2015;25(5):594-604.

34. Monti JM, Voss MW, Pence A, McAuley E, Kramer AF, Cohen NJ. History of mild traumatic brain injury is associated with deficits in relational memory, reduced hippocampal volume, and less neural activity later in life. Front Aging Neurosci. 2013;5:1-9.

35. Buckmaster PS, Schwartzkroin PA. Hippocampal mossy cell function: a speculative view. Hippocampus. 1994;4(4):393-402.

36. Rowe RK, Griffiths DR, Lifshitz J. Midline (central) fluid percussion model of traumatic brain injury. In: Kobeissy FH, Dixon CE, Hayes RL, Mondello S, editors. Injury models of the central nervous system: methods and protocols. New York: Springer New York; 2016. p. 211-30. https://doi.org/10. 1007/978-1-4939-3816-2_13.

37. Griesbach GS, Hovda DA, Gomez-Pinilla F, Sutton RL. Voluntary exercise or amphetamine treatment, but not the combination, increases hippocampal brain-derived neurotrophic factor and synapsin I following cortical contusion injury in rats. Neuroscience. 2008;154(2):530-40 Available from: http://www.ncbi.nlm.nih.gov/pubmed/18479829. [cited 2019 Dec 9].

38. Griesbach GS, Sutton RL, Hovda DA, Ying Z, Gomez-Pinilla F. Controlled contusion injury alters molecular systems associated with cognitive performance. J Neurosci Res. 2009;87(3):795-805 Available from: http://doi. wiley.com/10.1002/jnr.21893. [cited 2019 Dec 9].

39. Ansari MA, Roberts KN, Scheff SW. A time course of contusion-induced oxidative stress and synaptic proteins in cortex in a rat model of TBI. J Neurotrauma. 2008;25(5):513-26 Available from: http://www.ncbi.nlm.nih. gov/pubmed/18533843. [cited 2019 Dec 9].

40. Scharfman HE. The enigmatic mossy cell of the dentate gyrus. Nat Rev Neurosci. 2016;17(9):562-75 Available from: http://www.nature.com/articles/ nrn.2016.87

41. Jinde S, Zsiros V, Jiang Z, Nakao K, Pickel J, Kohno K, et al. Hilar mossy cell degeneration causes transient dentate granule cell hyperexcitability and impaired pattern separation. Neuron. 2012;76(6):1189-200. https://doi.org/ 10.1016/j.neuron.2012.10.036.

42. Bui AD, Nguyen TM, Limouse C, Kim HK, Szabo GG, Felong S, et al. Dentate gyrus mossy cells control spontaneous convulsive seizures and spatial memory. Science. 2018;359(6377):787-90 Available from: http://www.ncbi. nlm.nih.gov/pubmed/29449490.

43. Gorse KM, Lafrenaye AD. The importance of inter-species variation in traumatic brain injury-induced alterations of microglial-axonal interactions. Front Neurol. 2018;9:1-12 Available from: https://www.frontiersin.org/ article/10.3389/fneur.2018.00778/full.

44. Wofford KL, Loane DJ, Cullen DK. Acute drivers of neuroinflammation in traumatic brain injury. Neural Regen Res. 2019:1-9.

45. Donat CK, Scott G, Gentleman SM, Sastre M. Microglial activation in traumatic brain injury. Front Aging Neurosci. 2017;28(9):208 Available from: http://journal.frontiersin.org/article/10.3389/fnagi.2017.00208/full. [cited 2019 Jun 30].

46. Takahashi K, Rochford CDP, Neumann H. Clearance of apoptotic neurons without inflammation by microglial triggering receptor expressed on myeloid cells-2. J Exp Med. 2005;201(4):647-57 Available from: http://www. ncbi.nlm.nih.gov/pubmed/15728241. [cited 2019 Jun 30].

47. Colton CA. Heterogeneity of microglial activation in the innate immune response in the brain. J Neuroimmune Pharmacol. 2009;4(4):399-418 Available from: http://link.springer.com/10.1007/s11481-009-9164-4. [cited 2019 Jun 30].

48. Simon DW, McGeachy MJ, Bayır H, Clark RSBB, Loane DJ, Kochanek PM. The far-reaching scope of neuroinflammation after traumatic brain injury. Nat Rev Neurol. 2017;13(3):171-91. https://doi.org/10.1038/nrneurol.2017.13.

49. Pierce JP, Melton J, Punsoni M, McCloskey DP, Scharfman HE. Mossy fibers are the primary source of afferent input to ectopic granule cells that are born after pilocarpine-induced seizures. Exp Neurol. 2005;196(2):316-31.

50. Zhang K, Sejnowski TJ. A universal scaling law between gray matter and white matter of cerebral cortex. PNAS. 2000;97(10):5621-6 Available from: www.pnas.org/cgi/doi/10.1073/pnas.090504197.

51. Bailey EL, Mcculloch J, Sudlow C, Wardlaw JM. Potential animal models of lacunar stroke: a systematic review. Stroke. 2009;40(6).

52. Howells DW, Porritt MJ, Rewell SSJ, O'Collins V, Sena ES, Van Der Worp HB, et al. Different strokes for different folks: the rich diversity of animal models of focal cerebral ischemia. J Cereb Blood Flow Metab. 2010;30(8):1412-31. https://doi.org/10.1038/jcbfm.2010.66.

53. Galbraith JA, Thibault LE, Matteson DR. Mechanical and electrical responses of the squid giant axon to simple elongation. J Biomech Eng. 1993:115(1):13 Available from: http://biomechanical.asmedigitalcollection.asme.org/article. aspx?articleid=1399018.

54. Cullen DK, Vernekar VN, LaPlaca MC. Trauma-induced plasmalemma disruptions in three-dimensional neural cultures are dependent on strain modality and rate. J Neurotrauma. 2011;28(11):2219-33 Available from: http://www.liebertonline.com/doi/abs/10.1089/neu.2011.1841.

\section{Publisher's Note}

Springer Nature remains neutral with regard to jurisdictional claims in published maps and institutional affiliations.

Ready to submit your research? Choose BMC and benefit from:

- fast, convenient online submission

- thorough peer review by experienced researchers in your field

- rapid publication on acceptance

- support for research data, including large and complex data types

- gold Open Access which fosters wider collaboration and increased citations

- maximum visibility for your research: over $100 \mathrm{M}$ website views per year

At BMC, research is always in progress.

Learn more biomedcentral.com/submissions 